\title{
Intestinal Coccidia in Cuban Pediatric Patients with Diarrhea
}

\author{
FA Núñez/ , OM González*, I González, AA Escobedo**, RA Cordoví
} Departamento de Parasitología, Instituto de Medicina Tropical "Pedro Kourí,, Apartado Postal 601, La Habana, Cuba *Hospital
Universitario Pediátrico del Cerro, La Habana, Cuba **Instituto de Gastroenterología y Policlínico del Vedado, La Habana, Cuba

From May to August 1999, we evaluated 401 patients from a pediatric hospital of Havana City. One group was composed of 113 patients with diarrhea admitted to the Gastroenterology ward and a second consisted of 288 patients without diarrhea, admitted for other reasons, and hospitalized within the same time period. Three stool samples were collected from each child and were examined using three parasitological techniques. When we compared the frequency of parasite species between both groups, we found Cryptosporidium spp. and Cyclospora cayetanensis, only in the group of children with diarrhea $(P<0.01)$. However, no significant differences were found in the occurrence of the other intestinal parasites $(P>0.05)$. In addition, in those children infected with Cryptosporidium, the diarrhea had a more prolonged duration $(P<0.01)$, while those infected with Cyclospora, the abdominal cramps or pain, and acute diarrhea were more frequently detected $(P<0.01)$. Our results showed that emerging intestinal coccidia are pathogens strongly associated in this group of children with diarrhea.

Key words: intestinal parasites - pediatrics patients - diarrhea - Cyclospora cayetanensis - Cryptosporidium spp. - Cuba

Diarrheal diseases affect millions of people throughout the world, having the greatest impact among children, especially those in developing countries (Bern \& Glass 1994), and are the leading causes of child mortality in various countries and regions (Mølbak et al. 1992). There is evidence that mortality from diarrhea is decreasing in several locations of the developing world (Bern et al. 1993), but morbidity has not decreased and is associated with substantial costs in terms of treatment and hospitalization (Bern \& Glass 1994).

Parasitism and diarrhea are both hyper-endemics in areas where sanitation is not optimal (Hashmey et al. 1996). There are several "new" intestinal parasites that have emerged during the last two decades. The coccidia Cryptosporidium spp. and Cyclospora cayetanensis have been clearly recognized as important causes of diarrhea during childhood (Griffiths 1998, Looney 1998), both micro-organisms are attracting more attention as important public health hazards (Marshall et al. 1997, Looney 1998). In the majority of countries, including developing regions, the lack of surveillance, and limited availability of appropriate diagnostic tests have hindered public health efforts to prevent and control outbreaks caused by these two waterborne protozoan pathogens (Marshall et al. 1997).

This report is part of a cross sectional survey carried out in a pediatric hospital, aiming to document etiological agents in hospitalized children with diarrhea, including bacteria and parasites; reports of bacteria will be published elsewhere.

\footnotetext{
${ }^{+}$Corresponding author. Fax: +53-7-2046051. E-mail: fan@infomed.sld.cu

Received 13 August 2002

Accepted 9 April 2003
}

The study was conducted between May and August of 1999 at the Pediatric Academic Hospital of Cerro, a hospital that provides medical care mainly to the pediatric population from the municipality of Cerro, in Havana City, Cuba. This time period is corresponding with the warmer and rainy season and it was chosen in view of the historically reported major number of children admitted with diarrhea, in the hospital during these four months.

We evaluated two distinct groups, one composed of all 113 patients admitted because of diarrhea to the Gastroenterology division and a comparison group composed of 288 patients admitted to the hospital for other reasons and hospitalized within the same time period. The children with diarrhea were admitted because of low or moderate dehydration or vomiting more than $24 \mathrm{~h}$. The comparison group was mainly composed of all children admitted to the pediatric surgery wards for elective surgery, whom had not had diarrheal illness in the last 15 days. Both groups had similar socio-economic status, as was previously ascertained by questionnaires. In the groups of patients with diarrhea the mean age was 2.3 years (S.D. \pm 5.3 ; range: $0-7$ years); while in the group of patients without diarrhea the mean age was 2.9 (S.D. \pm 5.8 ; range: $0-9$ years); in the group of patients with diarrhea $59(52.2 \%)$ were males and $54(47.8 \%)$ were females, while in the group of patient without diarrhea $155(53.8 \%)$ were males and $133(46.2 \%)$ were females. No statistically significant differences were found between sex and age of these two groups $(P>0.05)$.

Three stool samples were collected from each child. Children who, for various reasons, failed to provide three stool specimens were excluded from the final analysis of data. This group was less than $5 \%$ of those completed the study. Two physicians interviewed the parents or guardians of the children to complete a questionnaire to record clinical and epidemiological data; medical records were 
also reviewed. The ethics committee of the hospital approved the study and informed consent was obtained from the parents of children who participated in the study.

Each parent or guardian was given three labeled plastic vials with $10 \%$ formalin solution and they were advised to collect three stool samples during an one-week period. All stool preserved samples collected were transported to the laboratory of Intestinal Parasites, in the Institute Pedro Kourí, in Havana, where they were examined for the presence of parasites by direct wet mount, formalin-ethyl acetate and the modified Ziehl-Neelsen techniques (Garcia \& Bruckner 1993). Furthermore, in all cases where the diagnosis of Cryptosporidium or Cyclospora was suspected with the sedimentation technique, the sediment was stained once more using the same modified ZiehlNeelsen method. The oocysts were identified according to the morphological characteristics and their sizes. Criteria used for the identification of $C$. cayetanensis were the presence of round unsporulated oocysts with greenish refractile globules from 8 to $10 \mu \mathrm{m}$ in diameter and the varying stain reactions from deep red with a mottled appearance, through pink to unstained glassy membranous bodies. In the majority of slides, the degree of staining varied in a single smear (Looney 1998). Bacteriological stool cultures were performed only for hospitalized patients with diarrhea, in the Clinical Microbiology laboratory of the hospital.

For the evaluation of categorical variables we used the Chi-square test. The Fisher exact test was used when required by data scarcity. The Mann-Whitney $U$ test was used to compare quantitative variables between two groups. $P$ values less than 0.05 were considered significant.

During the four months of the study, 1,203 stool samples from 401 children were examined, 339 samples from 113 children with diarrhea and 864 samples from 288 children without diarrhea. In the group of 113 patients admitted with diarrhea, $35.4 \%$ (40/113) were diagnosed with infectious pathogens. Twenty-one percent $(24 / 113)$ of these patients had parasitic pathogens.

Table I shows the comparison between the frequency of intestinal parasitic species in the group of children admitted for diarrhea and the group of children without diarrhea hospitalized for other reasons during the same period of time. Interestingly, C. cayetanensis and Cryptosporidium, were detected only in children admitted for diarrhea $(P<0.01)$, but they were not diagnosed in patients without diarrheal illness. Moreover, there were no significant differences in the occurrence of the other intestinal parasites between both groups $(P>0.05)$.

We detected a high number of children infected with parasitic pathogens. However, it is a well known fact that the finding of an etiological agent in a child with diarrhea does not necessarily mean that this pathogen is the cause of the illness, and that the diarrhea may have been caused by another pathogen. In the majority of studies, even with the most rigorous techniques, $30-70 \%$ of episodes of diarrhea cannot be associated with a known pathogen (Bern \& Glass 1994, Hines \& Nachamkin 1996).

A limitation of our study could be our inability to detect mainly viral agents with the techniques used in our
TABLE I

Frequency of species of intestinal parasites diagnosed from 113 pediatric patients with diarrhea and 288 children without diarrhea

\begin{tabular}{lcc}
\hline & \multicolumn{2}{c}{ No. and (\%) of } \\
\cline { 2 - 3 } Infections with & $\begin{array}{c}113 \text { patients with } \\
\text { diarrhea }\end{array}$ & $\begin{array}{c}288 \text { patients } \\
\text { without diarrhea }\end{array}$ \\
\hline Protozoa & $6(5.3)$ & $29(10)$ \\
Giardia lamblia & $13(11.5)$ & $0(0) b$ \\
Cryptosporidium spp. & $5(4.4)$ & $0(0) b$ \\
Cyclospora cayetanensis & $16(14.1)$ & $61(21.2)$ \\
Blastocystis hominis ${ }^{b}$ & & \\
Helminths & $0(0)$ & $5(1.7)$ \\
Ascaris lumbricoides & $1(0.9)$ & $5(1.7)$ \\
Trichuris trichiura & $0(0)$ & $1(0.3)$ \\
Hookworm & $0(0)$ & $1(0.3)$ \\
Strongyloides stercoralis &
\end{tabular}

$\bar{a}$ : protozoan with controversial pathogenicity; $b$ : Fisher exact test, $P<0.01$

investigation design. However, we think that intestinal coccidia showed an important pathogenic role in those patients due to the strong association when we compared the group of children with gastroenteritis with the rest of children without this clinical condition. In addition, none of the 18 patients infected with coccidia parasites were found infected with bacterial pathogenic agents. Moreover an improvement in the stool consistency was noted during the first $72 \mathrm{~h}$ of treatment with azithromycin and trimethoprim-sulfamethoxazole for children infected with Cryptosporidium and C. cayetanensis respectively; and oocysts of both coccidia could no longer be identified in the stools after 3 days of therapy. We used azithromycin therapy in these children despite of this is not a standard practice in our national system of Public Health because all of them were inpatients with persistent diarrhea, in which another infectious pathogen was not detected. In addition, we took into account the good results obtained previously with this drug in tissue culture, experimental rodents, few clinical trials, and some encouraging anecdotal reports (Griffiths 1998, Allam \& Shehab 2002).

Table II summarizes some clinical characteristics of the two intestinal parasitic infections (C. cayetanensis and Cryptosporidium) associated with diarrhea in these children. The duration of diarrhea was longer in children infected with Cryptosporidium (22.2 \pm 5.97 days) than in those infected with Cyclospora (7.2 \pm 6.14 days; MannWhitney $U$ test, $P<0.01)$. Significantly, the patients infected with Cryptosporidium were more likely to have persistent diarrhea $(P<0.01)$, while acute diarrhea was more prevalent in the other group $(P<0.01)$. Previous studies have showed that the most important etiological agents associated with persistent diarrhea in children are enteroaggregative Escherichia coli and C. parvum. (Mølbak et al. 1992, Lima \& Guerrant 1992, Guerrant 1994). Despite the reports of a longer duration of diarrhea in children with Cyclospora, (Marshall et al. 1997, Looney 1998) we unexpectedly found that almost all children in- 
TABLE II

Some clinical characteristics associated with Cyclospora and Cryptosporidium detection in children with diarrhea

\begin{tabular}{|c|c|c|}
\hline \multirow[b]{2}{*}{$\begin{array}{l}\text { Clinical } \\
\text { characteristics }\end{array}$} & \multicolumn{2}{|c|}{ No. and (\%) of } \\
\hline & $\begin{array}{c}13 \text { children } \\
\text { infected with } \\
\text { Cryptosporidium } \\
\text { spp. }\end{array}$ & $\begin{array}{l}5 \text { children } \\
\text { infected with } \\
\text { Cyclospora } \\
\text { cayetanensis }\end{array}$ \\
\hline Fever & $6(46.1)$ & $2(40.6)$ \\
\hline Vomiting & $7(53.8)$ & $3(60)$ \\
\hline Abdominal cramps or pain & $0(0)$ & $4(80)^{a}$ \\
\hline Anorexia & $7(53.8)$ & $1(20)$ \\
\hline Acute diarrhea & $0(0)$ & $4(80)^{a}$ \\
\hline Persistent diarrhea & $13(100)$ & $1(20)^{a}$ \\
\hline \multicolumn{3}{|l|}{ Duration of diarrhea (days) } \\
\hline Range & $16-37$ & $3-18$ \\
\hline Mean $( \pm$ SD $)$ & $22.2( \pm 5.97)$ & $7.2( \pm 6.14)^{b}$ \\
\hline \multicolumn{3}{|l|}{ Ages (years) } \\
\hline Range & $0-2$ & $0-8$ \\
\hline Mean $( \pm \mathrm{SD})$ & $0.5( \pm 0.78)$ & $3.2( \pm 3.96)$ \\
\hline
\end{tabular}

$a$ : Fisher exact test, $P<0.01 ; b$ : Mann-Whitney $U$ test $P<0.01$

fected with this protozoan had acute diarrhea. Nevertheless, due to the scarce number of cases that we detected, we cannot draw firm conclusion regarding this clinical finding. We suggest that another study, with a large number of cases, would be necessary in order to elucidate this and other clinical and epidemiological characteristics of diarrhea in Cuban pediatric inpatients infected with Cyclospora.

There were not differences found in the mean age between the groups of children infected by Cyclospora and the group of children infected with Cryptosporidium $(P>$ $0.05)$ and this result could be due to small number of cases. However, all 13 children affected by Cryptosporidium were less than 2 years of age and the majority of them $(69.2 \%)$ were infants $(P<0.05)$. These results also corroborate with the point-prevalence of cryptosporidiosis, which has been reported lower than that in children with cyclosporiosis. Previous studies, carried out in other countries have indicated that Cryptosporidium infection does occur in infants less than two years of age (Enriquez et al. 1997, Agnew et al. 1998). This could be explained by the immunologic immaturity (Agnew et al. 1998) or the increased likelihood of fecal-oral transmission due to behavioral characteristics of toddlers (Enriquez et al. 1997).

We found that some cases of cyclosporiosis occurred in children older than 6 years of age. A previous study developed in Guatemala showed that the prevalence of this coccidian was five times higher among children 1.5 to 9 years of age than in adults, and this infection was relatively uncommon among children less than 18 months (Bern et al. 1999). Another study carried out in Indonesia showed a higher frequency of Cyclospora infections in adult foreign residents and the absence of infections in young children with diarrhea. The authors explained that this might be due to the lack of exposure to foods or other risk factors to which older children and adults are exposed (Fryauff et al. 1999).

The results of the study might be different if we were conducted this throughout the year. Seasonal trends have been reported in cryptosporidiosis (Griffiths 1998) and cyclosporiosis (Bern et al. 1999) with the highest number of cases reported in warm or wet seasons. However, we do not know how would be this possible seasonality in our country where the high summer temperatures might be a critical environmental factor.

With regard to the other clinical findings we found that abdominal cramps or pain were more frequently detected in children affected by Cyclospora infection than those infected with Cryptosporidium $(P<0.01)$. However, this last group was composed mainly with infants whom are unlikely to report abdominal cramps. Previous studies have also documented this as one of the most important symptoms associated with confirmed cases of cyclosporiosis (Marshall et al. 1997, Herwaldt \& Ackers 1997, Katz et al. 1999).

There are few studies published on the prevalence of Cryptosporidium in Cuban children with diarrhea (Núñez \& Finlay 2001), but these reports lacked control groups and did not investigate the association with other parasitic agents. To our knowledge, this is the first report where both coccidia are isolated as the main pathogens associated with diarrhea in the same group of pediatric inpatients.

It is a known fact that in most laboratories, routine stool examination for ova and parasites does not include the special procedures needed to identify intestinal coccidia (Marshall et al. 1997, Roberts et al. 1996, Núñez \& Finlay 2001). However, our results clearly identify the emerging intestinal coccidia as parasitic pathogens commonly associated with diarrhea in this group of pediatric patients. Taking into account the above mentioned, we would recommend that all specimens submitted for routine parasitological examinations in Cuban children admitted because of diarrhea should be routinely tested for these emerging pathogenic organisms.

\section{REFERENCES}

Agnew DG, Lima AAM, Newman RD, Wuhib T, Moore RD, Guerrant RL, Sears CL 1998. Cryptosporidiosis in Northeastern Brazilian children: association with increased diarrhea morbidity. J Infect Dis 177: 754-760.

Allam AF, Shehab AY 2002. Efficacy of azithromycin, praziquantel and mirazid in treatment of cryptosporidiosis in school children. J Egypt Soc Parasitol 32: 969-978.

Bern C, Glass RI 1994. Impact of diarrheal disease worldwide. In AZ Kapikian, Viral Infections of the Gastrointestinal Tract, 2nd ed., Marcel Dekker, New York, p. 1-26.

Bern C, Hernandez B, Lopez MB, Arrowood MJ, de Mejia MA, de Merida AM, Hightower AW, Venczel L, Herwaldt BL, Klein RE 1999. Epidemiologic studies of Cyclospora cayetanensis in Guatemala. Emerg Infect Dis 5: 766-774.

Bern C, Martinez J, Zoysa I, Glass RI 1993. Magnitud del problema global de las enfermedades diarreicas: actualización decenal. Bol Of Sanit Panam 115: 523-535.

Enriquez FJ, Avila CR, Santos JI, Tanaka-Kido J, Vallejo O, Sterling CR 1997. Cryptosporidium infections in Mexican children: clinical, nutritional, enteropathogenic, and diagnostic evaluations. Am J Trop Med Hyg 56: 254-257. 
Fryauff DJ, Krippner R, Prodjodipuro P, Ewald C, Kawengian S, Pegelow K, Yun T, von Heydwolff-Whenert S, Oyofo B, Gross R 1999. Cyclospora cayetanensis among expatriate and indigenous populations of West Java, Indonesia. Emerg Infect Dis 5: 585-588.

Garcia LS, Bruckner DA 1993. Diagnostic Medical Parasitol$o g y, 2$ nd ed., American Society for Microbiology, Washington DC, p. 501-540.

Griffiths JK 1998. Human cryptosporidiosis: epidemiology, transmission, clinical disease, treatment, and diagnosis. $A d v$ Parasitol 40: 37-85.

Guerrant RL 1994. Twelve messages from enteric infections for science and society. Am J Trop Med Hyg 51:26-35.

Hashmey R, Genta RM, White Jr AC 1996. Parasites and diarrhea. I: Protozoans and diarrhea. J Travel Med 4: 17-31.

Herwaldt BL, Ackers ML, Cyclospora Working Group 1997. An outbreak in 1996 of cyclosporiasis associated with imported raspberries. $N$ Engl J Med 336: 1548-1556.

Hines J, Nachamkin I 1996. Effective use of the clinical microbiology laboratory for diagnosing diarrheal diseases. Clin Infect Dis 23: 1292-1301.
Katz D, Kumar S, Malecki J, Lowdermilk M, Koumans EHA, Hopkins R 1999. Cyclosporiasis associated with imported raspberries, Florida, 1996. Public Health Rep 114: 427-438.

Lima AAM, Guerrant RL 1992. Persistent diarrhea in children: epidemiology, risk factors, pathophysiology, nutritional impact, and management. Epidemiol Rev 14: 222-242.

Looney WJ 1998. Cyclospora species as a cause of diarrhoea in humans. Br J Biomed Sci 55: 157-161.

Marshall MM, Naumovitz D, Ortega Y, Sterling CR 1997. Waterborne protozoan pathogens. Clin Microb Rev 10: 67-85.

Mølbak K, Aaby P, Ingholt L, Højlyng N, Gottschau A, Andersen H, Brink L, Gansted U, Permin A, Vollmer A, da Silva APJ 1992. Persistent and acute diarrhoea as the leading causes of child mortality in urban Guinea Bissau. Trans $R$ Soc Trop Med Hyg 86: 216-220.

Núñez FA, Finlay CM 2001. Training for diagnosis of intestinal parasitic diseases in the national laboratory system of Cuba. Cad Saúde Pública 17: 719-724.

Roberts CL, Morin C, Addiss DG, Wahlquist SP, Mshar PA, Hadler JL 1996. Factors influencing Cryptosporidium testing in Connecticut. J Clin Microbiol 34: 2292-2293. 